\title{
Delphine de Mme de Stäel o un alegato contra la norma imperante
}

\section{(Mme de Stäel's Delphine, or a plea against the dominant norm)}

\author{
Cristina Huertas Abril y Beatriz Martínez Ojeda \\ 152huabc@uco.es / I22maojb@uco.es \\ G. I. Hum-198 (Lexicografía y Traducción Literaria)
}

\begin{abstract}
Fecha de recepción: 13 de septiembre de 2012
Fecha de aceptación: 15 de octubre de 2012
\end{abstract}

Resumen: El comienzo del siglo XIX francés se encuentra marcado por la euforia derivada del triunfo de la revolución. No obstante, los acontecimientos históricos pronto mostrarían que lo alcanzado en cuanto a libertades fue, en realidad, un fracaso que desencantó a la sociedad. En la literatura, a su vez, se produce el paso de la llustración al Romanticismo, donde la razón queda subordinada a los sentimientos. En este contexto encontramos a Madame de Stäel, una figura de gran importancia literaria y política, cuyas obras ponen de relieve las inquietudes de la mujer aristocrática del siglo XIX. En este trabajo pretendemos realizar un estudio de los principales elementos feministas de su novela epistolar Delphine (1802), así como de algunos aspectos destacados de la traducción al español realizada por Juan Ángel Caamaño.

Palabras clave: Delphine. Mme de Stäel. Novela epistolar. Literatura feminista. Traducción literaria. Romanticismo francés.

Abstract: The early nineteenth century in France is characterized by the euphoria derived from the revolution. Nevertheless, the historical events soon showed that the freedom reached was just a social failure. The literary context witnesses the transition from the Enlightenment to Romanticism, where sentiments flourish to the detriment of the reason. Mme de Stäel, a relevant literary and political figure, highlighted in her works the worries of the nineteenth century aristocrat women. This paper aims to study the main feminist features of her epistolary novel, Delphine (1802), together with some relevant reflections from the translation into Spanish carried out by Juan Ángel Caamaño.

Key words: Delphine. Mme de Stäel. Epistolary novel. Feminist literature. Literary translation. French Romanticism.

\section{INTRODUCCIÓN}

La novela en Francia conocerá durante el siglo XVIII un auge considerable, hasta el punto de convertirse en un género literario mayor o en el género por excelencia que más tarde llegaría a ser. Liberándose prácticamente dos siglos, y rechazando someterse a formas fijas, llegará a 
ser el género de moda, atendiendo a una doble divisa: variedad y libertad. Según Marthe Robert (1972: 14), su poder se explica por la capacidad del género para tratar sobre todo tipo de cuestiones y problemas, por su flexibilidad y por las nuevas formas adoptadas por los novelistas:

\begin{abstract}
Avec cette liberté du conquérant dont la seule loi est l'expansion indéfinie, le roman qui a aboli une fois pour toutes les anciennes formes classiques (...) s'approprie toutes les formes d'expression, exploite à son profit tous les procédés. II s'empare de secteurs de plus en plus vastes de l'expérience humaine dont il donne une reproduction en l'interprétant à la façon du moraliste, d'historien, du théologien, du philosophe.
\end{abstract}

Sin embargo, durante los siglos XVII y XVIII, la novela había sido menospreciada, siendo objeto de interminables y violentas reprobaciones y censuras: hombres de religión, filósofos e incluso novelistas no cesaban de denigrarla y condenarla. El cambio ya empieza a producirse con Diderot (1818: 600), que en 1761 afirmará contundentemente:

Par un roman, on a entendu jusqu'à ce jour un tissu d'événements chimériques et frivoles, dont la lecture était dangereuse pour le goût et pour les mœurs. Je voudrais bien qu'on trouvât un autre nom pour les ouvrages de Richardson, qui élèvent l'esprit, qui touchent l'âme, qui respirent partout l'amour du bien, et qu'on appelle aussi des romans.

A finales de siglo, el Dictionnaire de la Académie Française (1798) la definirá del siguiente modo: "Ouvrage ordinairement en prose, contenant des fictions qui représentent des aventures rares dans la vie et le développement entier des passions humaines".

De un modo curioso, y a pesar de todas las reprobaciones y admoniciones soportadas por el género novelístico, será el que mejor resista a las turbulencias de la historia del país francés, ocurriendo un hecho relevante y en parte paradójico: será el único género que atraviese la Revolución Francesa sin aparente daño ni secuelas, y con los mismos caracteres en 1760, en 1790, en 1800 o en 1820, y esto a pesar de la casi desaparición de nuevos títulos entre 1793-1794.

La escasa producción en todos los géneros literarios que trae como consecuencia la Revolución y el Imperio, etapas en las que Napoleón domeña voluntades y libertades, va a propiciar un surgimiento notable de una clase social en el mundo de las letras: ante la restricción de ideas y pensamientos a todos los hombres de letras, la mujer, que no era tan sospechosa de predicar o adoctrinar con la pluma como lo había sido el hombre, va a emerger como ente social. De este modo, la literatura de 
narración se convierte en el terreno predilecto de las novelistas, sobre todo en Francia y en los países francófonos, donde surgen mujeres de una clase social alta, bien por ascendencia, bien por casamiento, que parecen aplicar la definición del diccionario citada y que reivindican describir en sus heroínas locas y furiosas pasiones. Así ocurre en las obras de Isabelle de Charrière (1740-1805), Ysabelle de Montolieu (1751-1832), Madame de Genlis (1746-1830), Madame de Krudener (1764-1824), Madame Cottin (1770-1807), Madame de Souza (1761-1836) y Madame de Staël (17661817). Esta última Anne-Louise Germaine Necker, baronesa Staël-Holstein, hija del banquero Necker, será la introductora del Romanticismo alemán en Francia. Sus novelas Delphine (1802) y Corinne ou l'Italie (1807) representan la defensa de la libertad de elección sentimental sobre los convencionalismos sociales y constituyen un alegato en favor de la libertad y el desarrollo de la mujer.

\section{LA FIGURA DE LA AUTORA}

Hija del famoso banquero Necker, así como del Siglo de las Luces, Mme de Staël vivió en una época en la que las mujeres tenían limitado el derecho al uso de la palabra, especialmente si se trataba de opinar acerca de filosofía o de política. Este hecho condicionaría toda su vida, al verse enfrentada a una personalidad tan opresora como la del Emperador, que la obligaría a exilios continuos debido a su filiación política y a su libre pensamiento, a lo que estaba acostumbrada desde muy temprana edad al asistir a las tertulias del Salón de su madre con los enciclopedistas y filósofos, así como a la compañía de los amigos del padre, reputado banquero ginebrino y ministro de Luis XVI.

Favorable a la Revolución en un primer momento, dado que le parecía favorecer el progreso al que ella aspiraba, debió pronto abandonar Francia tras arriesgar su vida en las masacres revolucionarias de 1792; de este modo, emigra y se instala en Londres y luego en el castillo de Coppet (Suiza), en las orillas del lago Leman. De vuelta a París en 1795, su liberalismo le atraerá la enemistad de Napoleón, que en 1803 le prohíbe acercarse a menos de cuarenta leguas de la capital, a la que no volverá hasta la caída del Emperador, aunque nunca dejaría de interesarse y comprometerse en la política francesa. En Suiza conocerá a Benjamin Constant, con quien mantendrá una relación sentimental hasta 1808.

Durante diez años alterna sus estancias en el castillo de Coppet con numerosos viajes: en 1804 conoce a Goethe y a Schiller en Alemania y emprende un viaje por Italia. De 1812 a 1813 recorre diversos países europeos, regresando a París donde reabre su Salón. Casada desde 1786 con el barón sueco de Staël-Holstein, se separará de él en 1800. En 1816 se casará en secreto con John Rocca, mas en febrero de 1817 sufre un 
ataque de parálisis y muere en julio de ese mismo año, siendo inhumada en su castillo de Coppet.

Sus dos novelas, Delphine y Corinne, ayudan a conocer mejor a esta excepcional mujer que se debatirá entre las exigencias del corazón y los deberes del esprit. Las dos inauguran el feminismo romántico, que más tarde se expandirá en el personaje y la obra de George Sand: la mujer es la encarnación ejemplar del individualismo del corazón, víctima a la vez de la atadura social y de la cobardía o impotencia masculina. A través de sus heroínas Mme de Staël se describe a sí misma, habiendo contribuido enormemente a la entrada del Romanticismo en Francia con sus obras teóricas, sobre todo gracias a De l'Allemagne (1813).

\section{DELPHINE}

La novela se desarrolla en París entre 1789 y 1792 . Delphine d'Albémar, una joven viuda educada por un tutor que le ha dado su apellido, sigue su modelo de "Homme des Lumières"; este, que ha combatido en la guerra de América, ha sabido enseñarle a su protegida a reflexionar por sí misma y a liberarse de los prejuicios o del yugo de la opinión de la gente. A la muerte de su tutor, Delphine ha adquirido un espíritu de libre examen, pero su libertad e independencia no evitan que se deje llevar por su bondad, haciendo y actuando de un modo que los demás condenan. Como adinerada, generosa e inteligente que es, su mayor deseo es contribuir a la felicidad de todos los que la rodean; de ahí que trate de arreglar el matrimonio de Matilde de Vernon (prima lejana y amiga de Delphine) con Léonce de Mondoville, llegado de España y que no conoce a su futura esposa.

Al encontrarse con Delphine, Léonce se enamora de ella, que a su vez lo hace de él. Numerosos obstáculos se oponen a su felicidad: celos, intrigas, y acontecimientos políticos; todo parece estar en contra de ellos. Comprometida por salvar el honor de un amigo, Delphine pierde a su amante, que celoso y contrariado se casa con Mathilde. Los amantes se reencuentran posteriormente, Delphine se disculpa y Léonce vuelve a recuperar su pasión por ella, sin embargo, al ver comprometida su reputación, este no se decide a divorciarse de Mathilde, aunque es consciente de la necesidad de tomar una decisión de forma inminente. Carcomida por la pena, Delphine entra en un convento: Léonce, por su parte, enviuda y parte en su busca. Desesperado por no conseguir lo que quiere se enrola en la guerra civil, siendo fusilado por los revolucionarios. Finalmente, Delphine, al enterarse, se suicida.

La novela epistolar Delphine (1802), la vida de una joven hermosa e inteligente que es víctima de una sociedad represiva, fue en parte una transposición de ideas expuestas en De la littérature. El éxito de Delphine la 
convertiría definitivamente en una escritora célebre y concitaría las iras de Napoleón por su denuncia de la falta de libertad de las mujeres para decidir sobre su propio destino y su reivindicación del divorcio (institución introducida en 1792, que el entonces cónsul vitalicio consideraba suprimir), así como sus críticas al despotismo y su elogio del libre examen protestante y la tolerancia religiosa. En 1804 tuvo que partir a un nuevo exilio, narrado en su obra póstuma Dix ans d'exil (1818).

La utilización en la novela de la forma epistolar representaría una gran ventaja para la autora en su afán de llegar al público lector y transmitirle sus ideas progresistas y feministas, ya que, manejada hábilmente y con discernimiento, la prosa epistolar ejerce un encanto indiscutible. A ello podía unirse la ventaja de que se adaptaba a la perfección a la imagen que reflejaba la vida cotidiana. El público de lectores prefería leer hechos reales, verosímiles, aventuras auténticas, relatos en una palabra, en los que la ficción estaba al servicio de la realidad. Gracias a su plasticidad, la fórmula epistolar ofrecía al novelista posibilidades ilimitadas, como ya apuntaba Montesquieu en «Quelques réflexions sur les Lettres persanes» (1838: 1):

Dans les romans ordinaires, les digressions ne peuvent être permises que lorsqu'elles forment elles-mêmes un nouveau roman. On n'y saurait mêler de raisonnements, parce qu'aucuns des personnages n'y ayant été assemblés pour raisonner, cela choquerait le dessein et la nature de l'ouvrage. Mais, dans la forme des lettres où les facteurs ne sont pas choisis, et où les sujets qu'on traite ne sont dépendants d'aucun dessein ou d'aucun plan déjà formé, l'auteur s'est donné l'avantage de pouvoir joindre de la philosophie, de la politique et de la morale à un roman, et de lier le tout par une chaîne secrète et, en quelque façon, inconnue.

En definitiva, la forma epistolar se prestaba a todo tipo de intrigas y se adaptaba a todo los tonos: desde el "roman sentimental" al "roman terrifiant" y al "récit libertin".

Publicada su novela cuando la autora tiene 36 años, en Delphine Mme de Staël trata de defender a la mujer, así como justificar su propio corazón y su conducta; era esta empresa ardua, ya que la justificación no tiene mucho sentido al no querer romper con la moral establecida y glorificar las faltas de Delphine al confesarlas, lo que habría sido más fácil convirtiendo a su heroína en una mujer culpable para luego absolberla con el pretexto de que ha amado con toda su alma.

La aparición de la novela suscitaría violentas y virulentas críticas, sobre todo por parte de periodistas y políticos, como si el Emperador hubiera tocado a rebato e iniciado una campaña infamante contra el 
feminismo esbozado en el relato. El ya mencionado Joseph Fiévée, en esa época corresponsal secreto de Napoleón, criticará las ideas feministas en un artículo aparecido en el Mercure de France (cit. Balayé, 1986: 41):

Delphine (...) est une tête exaltée ; (...) elle est philosophe et déiste, et, ce qui est pis, elle est si bavarde, qu'elle parle toujours la première. Parler est pour elle le bonheur suprême (...) Ce caractère existe, et Madame de Staël a pu le peindre ; mais elle a eu tort de croire qu'une femme pareille inspirerait de l'intérêt.

De igual modo, el abogado y político Pierre-Louis Roederer, califica a la protagonista de indecente, escribiendo lo siguiente sobre su atracción por Léonce de Mondoville (cit. en Balayé, 1986: 42):

Une femme qui se laisse approcher ainsi est déjà souillée, l'adultère est là, dans l'embrasement de deux imaginations qui ne peuvent plus s'attacher à aucun devoir, ni tenir dans aucune vertu.

Actualmente, las ideas contenidas en la novela, que son solo el germen de la posterior revolución feminista que se iniciaría en Estados Unidos un siglo y medio más tarde, son contempladas con toda benevolencia y comprensión, a pesar de que las novelas de Mme de Staël sean las que más han envejecido de toda su obra, siendo mucho más actual su ensayo De l'Allemagne, que contribuiría en buena parte al triunfo del Romanticismo en Francia.

\section{1. Mme de Stael narradora y la influencia de la traducción de sus obras} en España

Las dos novelas de Mme Staël tendrían un amplia difusión en España, aunque bastante más Corinne que Delphine. Traducidas ambas por D. Juan Angel Caamaño ${ }^{1}$, Delfina se publicaría en seis volúmenes en Burdeos con un curioso subtítulo (La opinión) y una cita en la portada a modo de exergo que advierte al lector del argumento de la novela:

El hombre debe saber arrostrar

la opinión, y la mujer sujetarse a su imperio.

\footnotetext{
1 Juan Ángel Caamaño (1789-1821) desempeñó diversos empleos públicos durante la Guerra de la Independencia y el inicio del Trienio Constitucional, actividades que compaginó con su labor como traductor y escritor de colaboraciones literarias en distintos periódicos. Su admiración por Mme de Stäel, unida a sus ideas liberales, le llevaron a traducir Corinne (Corina, ó Italia, 1820) y Delphine (Delfina o la opinión, publicada póstumamente en 1828), así como a reseñar también su ensayo acerca de la traducción para El Constitucional.
} 
El prólogo de Corina de la traducción de D. Juan Ángel Caamaño, constituye un buen testimonio de la temprana difusión en España de las ideas sobre la oposición entre clásicos y románticos que Mme de Staël había expuesto en De l'Allemagne. La versión de Corinne de Caamaño, anunciada por el editor Mariano de Cabrerizo unos años antes de su publicación y que tuvo problemas con la censura, se publicó después de la de Pedro María Olive (1818), mucho más libre. A este último alude el prólogo cuando se refiere a «vimos anunciar y darse a luz el primer tomo de Corina, con evidente intención de inutilizar nuestro trabajo».

Por su importancia para la recepción de sus obras y de la propia autora, así como de las nuevas ideas románticas que entraban en nuestro país, como por las interesantes consideraciones sobre la tarea del traductor, merece la pena su entera transcripción (cit. Mme de Stäel, 1820:1-3):

El nombre de Mad. Staël bastaría para dar concepto de una obra de literatura a cuantos conocen el mérito singular de sus producciones, que la han hecho realmente la gloria de su sexo, probando acaso más que todos los argumentos tantas veces repetidos, cuanto influye la educación en la diferencia intelectual de las dos mitades del linaje humano: empero además su Corina es celebrada en todos los países civilizados, no solo como novela interesantísima, en que respetando siempre con la mayor delicadeza las leyes santas de la moral, se desenvuelven los más ocultos misterios del corazón y de las pasiones, sino como un viaje pintoresco a las regiones más bellas, como una representación viva de las memorias de la antigua Italia, y una pintura hermosísima de la moderna. Sin embargo, los defensores severos, los adoradores intolerantes de la literatura que llaman clásica, no han querido ceder de sus rigurosos principios, siquiera en favor de la infeliz y encantadora Corina; pertenece a la literatura romántica, a esa literatura proscripta, a esa literatura nacida del cristianismo, que se condena por no haberla conocido Horacio, y basta; no puede merecer compasión ni aprecio. En vano presentará en su heroína esta novela toda la grandeza del talento, unida a toda la sencillez, a toda la ternura, a toda la pureza del corazón; en vano se verá en lord Nelvil todo el extremo del cariño filial, y toda la nobleza de un carácter elevado; en vano se hallará en Lucila el candor y el recato más amables; en vano sentirán los lectores, sin querer, elevarse su alma en los primeros libros, a la vista de las ruinas descritas por Corina, y correr sus lágrimas al ver caída a la Sibila del carro triunfal al abismo de los dolores; nada es bello, nada es tierno, nada es natural, porque no es clásica.

Así se engañan los hombres a sí mismos, así se niegan a recibir el testimonio de su propio talento y de su propia sensibilidad, cuando se empeñan en vanas disputas, sin detenerse a definir las voces, único 
fundamento tal vez, de su diferencia. ¿Qué se entiende en efecto por literatura clásica? ¿Entiéndese la que corresponde exacta y propiamente a ciertos modelos, o la que llena el objeto de la literatura? ¿No se puede hallar el arte de agradar y de conmover sino imitando a los prototipos de los clásicos? ¿Y agradar y conmover no son las primeras, quizá las únicas circunstancias que hay que elegir en toda obra de literatura? ¿Quién se halla autorizado para señalar límites al entendimiento humano? ¿Quién puede decir ya lo sabemos todo, y pretender, como dice Mad. Staël, levantar a nuestro alrededor la gran muralla de la China, para impedir la entrada a las ideas literarias de otras naciones?

La voz clásico, como que es una abstracción, puede tener varias acepciones; por tanto, para hablar con juicio de la literatura clásica, y de la romántica, es menester fijar primero el sentido que se le quiere dar. Efectivamente, unos la usan como sinónimo de perfección, y otros la aplican solo a la poesía de los antiguos. En el primer caso, la misma perfección consiste, según ellos, en la rigorosa observancia de las reglas de cierta escuela; en el segundo no se permite más que imitar a los modelos griegos y latinos, pues un poema épico, por ejemplo, ha de parecerse a Homero a Virgilio, ha de corresponder a todos los versos del arte poética de Horacio, y a todas las glosas de sus innumerables comentadores, o ha de ser romántico; esto es, pésimo según la opinión de la falange de los preceptistas. Así pues estos maestros del gusto, estos campeones de la literatura clásica, ponen el entendimiento humano en la misma situación que se hallaría un hombre rodeado por todas partes de lazos que le estorbasen cualquier movimiento, y a quien se mandase, no obstante, caminar con velocidad y gallardía. Así proscriben sin ninguna excepción la literatura de la edad media, proscriben en masa la literatura alemana, la literatura inglesa, la literatura española y cuanto presenta la imaginación libre de prisiones: gracias a su doctrina, ya no aparece en el vasto campo de la literatura nada original, nada que no sea amanerado, nada que merezca la atención de un hombre profundo, ni enternezca á un hombre sensible.

Cuando los defensores del gusto que ellos Ilaman clásico, hablan del Ariosto, del Dante, del Shaquespeare, de Calderón, no atreviéndose a negarles talento y fantasía, atribuyen a ignorancia la falta de sujeción a las reglas: pero los románticos modernos ¿son hombres ignorantes? Goëthe, Schiller, Schlegel; sobre todo, Schlegel, a quien los pretendidos clásicos miran con más rencor; Schlegel, que ha traducido en su lengua a Shaquespeare y a Calderón; Schlegel que ha escrito un curso de literatura dramática que abraza todas las producciones teatrales desde los griegos basta nuestros días, ¿no sabe esas reglas que repite de memoria cualquier discípulo de un colegio? ¿no conoce todos los autores, todas las obras maestras de la antigüedad que se llaman clásicas? No obstante, es partidario del gusto romántico sin dejar por eso de reconocer las bellezas sublimes de los antiguos, 
porque conoce que es un empeño ridículo quererlos tomar rigorosamente por modelos, cuando la Religión, el gobierno, las costumbres, la vida doméstica, todo es diverso entre nosotros, cuando los progresos del entendimiento humano en 18 siglos han hecho desaparecer todas las opiniones, y todas las riquezas de la poesía griega y romana, dejando solo hermosos monumentos dignos por cierto de admiración, como el coliseo y los obeliscos egipcios en Roma; mas que es en vano pretender imitar.

Los defensores del gusto clásico, no quieren de modo alguno reconocer la alteración que debió causar en las ideas literarias el establecimiento de la religión cristiana, tan diferente en sus dogmas, y tan diversa en su objeto de la de los gentiles. El paganismo personificaba todos los objetos, y hasta los sentimientos del alma; cada árbol era una Amadriada, cada prado, cada fuente, cada bosque una Driada, una Náyade, una Nereida; si un corazón tierno palpitaba de amor, era Cupido quien le había traspasado con flecha inevitable; si un hombre feroz se entregaba a todo el frenesí del odio, eran las furias quien le agitaban; si el sueño rendía suavemente un ánimo inquieto, era porque Morfeo derramaba sobre sus párpados adormideras; en fin todas las ideas de aquellos hombres se dirigían a lo exterior, en ninguna parte se hallaban solos, porque su rica fantasía había animado todo el universo. No así la religión cristiana, esta religión fundada en la moral, en la meditación y en el dolor, llama siempre al hombre dentro de sí; descúbrele lo inmenso, lo infinito, lo eterno, y revelándole el secreto de sus altos destinos; presentándole en el ejemplo de su divino fundador la imagen del sufrimiento, le manda referirlo todo a su alma, y estudiar todos sus secretos impulsos. He aquí pues la diferencia de las dos literaturas, no clásica y romántica, sino antigua y moderna: los gentiles lo veían todo en la tierra, los cristianos lo vemos todo en el cielo, porque, como dice Corina, no hay mas queda dos modos muy distintos de sentir la naturaleza; animarla como los antiguos, y perfeccionarla con mil formas brillantes, o dejarse llevar como los Bardos escoceses del temor del misterio, y de la melancolía que inspira lo desconocido.

$\mathrm{Si}$ ahora se nos preguntase cuál de estas dos literaturas es mejor, diremos que cada una tiene sus bellezas y sus defectos, y que ambas, deberían tomar una de otra para ser verdaderamente clásica, esto es, perfectas, los románticos ganarían mucho en sujetarse a algunas reglas, poquísimas a la verdad fundadas en la naturaleza, y los clásicos lograrían grandes ventajas de dar más libertad a la imaginación en general, y en particular al carácter propio de cada nación.

Prescindiendo ahora de esta cuestión, que es para tratada mas largamente, y que solo hemos tocado por desvanecer la impresión, que la voz romántico puede causar a los que juzgan de las cosas por dictamen ajeno, y no por su propio estudio; pasaremos a hablar de otras circunstancias relativas a nuestra traducción. 
En el prospecto del editor se anunciaron las novelas de que había de constar la colección, no solo por dar idea, como nos pareció justo, de las obras al público, sino para evitar, obrando con la buena fe propia de cuantos se ocupan en especulaciones literarias, que algún otro se perjudicase, y nos perjudicara dedicándose a traducirlas. Sin embargo, muy lejos de realizarse nuestros deseos, mientras la estúpida ignorancia detenía la publicación de las novelas anunciadas, vimos anunciar y darse a luz el primer tomo de Corina, con evidente intención de inutilizar nuestro trabajo, y comprometernos con nuestros subscriptores. La moderación de que presumimos no nos permite hablar de aquella traducción, ni compararla con la nuestra; al público pertenece juzgar de las dos; pero no hemos creído deber en vista de ella, decir con Horacio:

\section{Frange, miser, calamos, vigilataque prælia dele!}

Las pocas supresiones o alteraciones del texto que se verán en nuestra traducción, se han fundado en motivos justísimos conocidos de cuantos han leído el original, porque escribimos para nuestros paisanos, y debemos acomodarnos á sus costumbres. También se hallarán en algunas partes voces, y sobre todo giros de frase menos atrevidos que los que usa Mad. Staël; no procede esto de haber desconocido su novedad y su belleza, sino de haberlas encontrado cierta forma demasiado germánica, si es lícito decirlo así, ajena a nuestra lengua a lo menos, mientras no se trabaje más en este estilo, y mientras los preceptistas, de otra especie que los clásicos, no consientan la ajustemos, sin alterar su índole, a los progresos de la literatura entre nosotros y en las demás naciones. A esto se reducen las variaciones que se hallarán en la presente traducción: hemos procurado ser escrupulosamente fieles cuando la autora pinta con ingeniosa delicadeza el carácter de sus héroes; cuando describe con valiente pluma las ruinas de Roma, la erupción del Vesubio, y las costumbres venecianas; cuando con incomparable ternura presenta su heroína en los días de la ausencia, de los celos y de la despedida postrera; en fin, hemos cuidado de conservar, como dicen nuestros vecinos, su fisonomía, en una obra en que acaso se ha retratado a sí misma, no solo en el carácter, sino en sus facciones vigorosas, en sus negros ojos y su negro cabello, y en su tez algo tomada del sol del mediodía.

Y por último, para no dejar nada por hacer en obsequio de los señores subscriptores que nos favorecen, hemos añadido a esta colección otra novela de la misma autora (Delfina ó la opinión), a fin de que reúnan las dos obras que en su clase han merecido más aprecio de todos los sabios de la Europa. 


\section{CONCLUSIÓN}

Tras la Revolución Francesa, en los primeros años del siglo XIX, la novela es el único género literario que parece poder expresar el alma de la época, más que la vida exterior y las costumbres. Algunos novelistas evocarían, de un modo muy agradable, como en un tono pastel, la Francia que su juventud había conocido, la de Luis XVI; de los acontecimientos y de los hombres de La Revolución y El Imperio no escriben casi nada. Podemos encontrar algunas páginas de Pigault-Lebrun ${ }^{2}$ sobre El Terror, de Fiévée ${ }^{3}$ sobre El Directorio, y de Mme de Souza ${ }^{4}$ sobre la emigración. En este sentido, Delphine es una obra curiosa y significativa, ya que la acción se desarrolla en París entre 1790 y 1792. El protagonista, Léonce de Mondoville, morirá en Chaumont, fusilado por los republicanos; sin embargo, Mme de Staël, que había asistido a las escenas más conmovedoras de La Revolución, parece como si no hubiera guardado recuerdo alguno en su memoria al escribir la novela. Así, la autora describe en varios pasajes las doctrinas de La Revolución y extrae las consecuencias morales, pero las peripecias y los actores del drama parecen totalmente al margen de aquella.

$Y$ es que, en realidad, lo que a la escritora le interesa es poner de relieve la fragilidad, la debilidad de la condición femenina respecto de los hombres. Ante los condicionamientos de la clase social, y no olvidemos que la suya es la más alta, Mme de Staël se rebela, adelantándose en su tiempo a la gran defensora de los derechos de la mujer en todos los campos: George Sand, aunque su rebelión sea solo un esbozo y no tenga la consistencia de esta última, que lleva a sus límites no solo en su obra sino por medio del ejemplo de su propia vida: si la mujer es una especie de muñeco para el hombre, de cuyas veleidades depende a lo largo de su vida, Sand va a devolverles su propia medicina utilizando sus encantos e inteligencia para seducirlos y comportarse con ellos como estos hacen con el sexo femenino.

\footnotetext{
${ }^{2}$ Charles-Antoine-Guillaume Pigault de l'Épinoy (1753-1835) fue un novelista y dramaturgo originario de Calais. Conocido principalmente por ceñirse a las extravagancias literarias en sus obras, como Charles et Caroline o L'Enfant du Carnaval, sus temporadas en prisión le llevaron a escribir sobre El Terror, concretamente Les Cent-vingt jours (1799).

${ }^{3}$ Joseph Fiévée (1767-1839) fue un periodista y escritor parisino, además de agente secreto francés. Durante la Revolución trabajó como impresor editando un destacado diario que le permitió dar sus primeros pasos como periodista: La Chronique de Paris. Fue prisionero durante El Terror y en la clandestinidad escribió La Dot de Suzette, gran éxito en 1798 al abordar los valores de la época, así como sus agitaciones.

${ }^{4}$ Adélaïde-Marie-Émilie Filleul (1761-1836) fue una escritora y moralista feminista, y salonnière parisina. Su novela más conocida, escrita tras la muerte de su esposo (guillotinado durante El Terror) es Adèle de Sénange ou Lettres de Lord Sydenham (1798).
} 
Está claro que la rebelión de Mme de Staël es solo un avance de los que más tarde ocurrirá, posiblemente debido a la pertenencia de su clase social, sometida a unas normas rígidas de comportamiento por una educación muy dirigida a su condición de mujer. De cualquier modo, el hecho de que la autora, a pesar de que hubiera podido llevar una vida placentera y rica en lo concerniente al espíritu, optara por no aceptar los sistemas imperantes de sometimiento de su sexo, e hiciera frente a la sociedad y al todopoderoso Emperador, demuestra una grandeza de miras fuera de lo común, como corresponde a una mujer excepcional en su vida y en su obra.

REFERENCIAS BIBLIOGRAFICAS

BALAYE, Simone. "Le Geste de dissimulation dans Delphine", Cahiers de l'Association Internationale des Études Françaises, 1973. . Madame de Staël. Lumières et Liberté. Paris: Klincksieck, 1979. . "Destin de femmes dans Delphine", en Cahiers Staéliens, oㅜ 35, 1984. "Delphine de Madame de Staël et la presse sous le Consulat", Romantisme, volume 16, n. 51, 1986, pp. 39-48.

CAAmaño, Juan Ángel. "Prólogo a Corina ó Italia", en Delfina o la opinión (trad. de Juan Ángel Caamaño). Valencia: Impr. Estevan, 1820. También disponible en línea en: http://www.saltana.org/1/esc/93.html [Fecha de última consulta: 9 de septiembre de 2012].

DIDEROT, Denis. "Éloge de Richardson, auteur des romans de Paméla, de Clarisse et de Grandisson", en CEuvres de Denis Diderot. Tome premier, $1^{\text {re }}$ partie. Paris: Chez A. Belin, Impr.-Libr., 1818, pp. 600-612.

DIDIER, Béatrice. "Le Paysage chez Mme de Staël", en Revue d'Histoire Littéraire de la France, janvier 1966.

DIESBACH, Ghislain de. Madame de Staël. Paris: Perrin, 1983 (2008).

EAUBONnES, Françoise (d'). Une femme témoin de son siècle, Germaine de Staël. Paris: Flammarion, 1966.

GarRY-Boussel, Claire. Statut et fonction du personnage masculin chez Madame de Staël. Honoré Champion, 2002.

GOODDEN, Angelica. Madame de Staël: the dangerous exile. Oxford: OUP, 2008.

GUTWIRTH, Madelyn. Madame de Staël, Novelist: The Emergence of the Artist as Woman. Urbana: University of Illinois Press, 1978.

Herold, J. Christopher. Germaine Necker de Staël. Paris: Plon, 1962.

LANG, André. Une vie d'orages, Germaine de Staël. Paris: Calmann-Lévy, 1958.

MONTESQUIEU, Charles Louis de Secondat, barón de. "Quelques réflexions sur les Lettres persanes", en CEuvres complètes. Paris: Chez Firmin Didot Frères, Libraires, Imp. de l'Institut de France, 1838, pp. 1-2. 
OMACINI, Lucia. "Quelques remarques sur le style des romans de Mme de Staël, d'après la presse de l'époque, 1802-1808”, en Annali di Ca' Foscari, Venezia, 1973.

ROBERT, Marthe. Roman des origines et origine du roman. Paris: Gallimard, 1972

SCHIFFER, Liesel. Femmes remarquables au XIX siècle. Paris: Vuibert, 2008.

STÄEL, Germaine Necker de. Delfina o la opinión (trad. de Juan Ángel Caamaño). Valencia: Impr. Estevan, 1820.

Delfina o la opinión (trad. de Juan Ángel Caamaño), 6 tomos, Bordeaux: Impr. D. Pedro Beaume, 1828.

Delphine (édition critique para Simone Balayé et Lucia Omacini). Genève: Droz, 1987.

WINOCK, Michel. Madame de Staël. Paris: Fayard, 2010. 